\title{
Metodological aspects in the studying of soil particle size distribution under contamination and after reclamation
}

\author{
Inna Zamulina*, Marina Burachevskaya, Saglara Mandzhieva, Tatiana Bauer, Anatolii \\ Barakhov, and Mahmoud Mazarji \\ Southern Federal University, prosp. Stachki, 194/1, Rostov-on-Don, 344090, Russian \\ Federation
}

\begin{abstract}
In this study, a model experiment was performed under artificial copper contamination of Haplic Chernozem soil. Following the introduction of granular activated carbon (GAC) and biocharin contaminated soil, data on the particle size distribution were obtained. The particle size distribution of Haplic Chernozem was determined by two different methods namely pipette method (PM) and laser diffraction method (LDM). For the LDM, changes in the composition of fractions of more than $0.01 \mathrm{~mm}$ were more obvious, while for PM, the main differences were of characteristic for the content of fine fractions less than $0.01 \mathrm{~mm}$.
\end{abstract}

\section{Introduction}

Soil pollution originated by industrial companies is a worldwide problem. The content of heavy metals (HMs) in soils is one of the indicators of anthropogenic load [1]. Controlling of these priority pollutants are of great concern [2]. The adsorption and desorption behavior of HMs in the soil media is an important factor that affects their distribution in solid and liquid phases [3]. HMs quickly and firmly adsorbed from solutions by surface soil particles [4]. Moreover, the adsorption of HMs by the soil significantly alters the physical and chemical properties of soils and their corresponding components. HM cations would alternatively affect the specific surface of soils, the microstructure of clay minerals, the thermodynamic state of moisture in clay minerals, and the mineralogical composition of the clay fraction [5]. Consequently, the structure of the soil is altered while its density increases, the overall porosity and water permeability decrease, and water and air conditions deteriorate.

The use of carbon sorbents is one of the most effective and inexpensive methods for soil reclamation, especially for those subjected to technogenic pollution. The introduction of carbon sorbents would alternate eventually the physical properties of the soil. The effect of sorbent additives applied to the soil may vary depending on one case to another. Lowdensity sorbents can reduce the density of soil. Another possible effect is in the case of low mechanical strength of the sorbents [6]. The use of organic matter appears to favor soil

* Corresponding author: ivzamulina@sfedu.ru 
water retention capacity through an increase in soil porosity and the mean pore size diameter [7].

Carbon sorbents additions to soil may enhance organo-mineral interactions via adsorption and/or ligand exchange reactions [8]. These adsorbents can also provide improvement and long-lasting environmental effects for mycorrhizal growth [9]. Besides, this can result in support of soil structure building processes [10].

The particle-size composition of soils is one of the most important basic properties of soils. It governs the ability to determine many other physical and chemical characteristics of the soil, as well [11]. Soil particle-size fractions, i.e., the percentage compositions of clay, silt, and sand, are widely used to classify soil texture and also estimate some hydraulic properties. Standard methods for grain-size analysis are based on sedimentation rates for the fine fractions and screening of the coarse fractions. The classical standard technique established using a pipette method (PM) for soil particle size analysis. Over recent decades, various new methods for grain-size analyses have been developed. The example of the most common method is laser diffractometry (LDM) [12].

In this regard, the characteristics of changes in the particle size distribution applied in cupper polluted Haplic Chernozem alongside introducing carbon sorbents were carried out by two methods of PM and LDM. The results would allow assessing the effect of carbon sorbents on the physical properties of the soil and especially the particle size distribution.

\section{Materials and Methods}

The upper layer $(0-20 \mathrm{~cm})$ of Haplic Chernozem from the specially protected natural area "Persianovskaya steppe" was taken. The sampling site was located far from possible sources of pollution. The soils for the experiment were dried and passed through a sieve with the opening of $2 \mathrm{~mm}$. 2-liter vegetation vessels with a closed drainage system were used for conducting model vegetation experiment. The vessels were poured with $2 \mathrm{~kg}$ of soil. Afterward, $\mathrm{Cu}$ was subjected in the form of metal oxide (in a dry state) at two different dose levels of 300 and $2000 \mathrm{mg} / \mathrm{kg}$ and thoroughly mixed. After 2 months of incubation, biochar and granular activated carbon (GAC) were added to contaminated soil at doses of $1 \%$ and $2.5 \%$. These doses were selected according to our previous results of the phytotest. The soil was incubated at a steady water content of $60 \%$ of the total field capacity. The temperature was maintained in a range between $20-22^{\circ} \mathrm{C}$ during the span of the experiment. After 4 months of incubation, two-row spring barley (Hordeum sativum distichum) of the Ratnik variety was seeded. Watering was carried out every other day in order to maintain the corresponding humidity at field moisture capacity $(60 \%)$. Following the completion of the plant's sampling in the phase of full ripeness, soil samples were taken from the entire volume of the vegetation vessel along with the root system.

The particle size distribution was determined by classical PM and the LDM methods followed by pyrophosphate sample preparation.

\section{Results and Discussion}

The results of the study of particle size distribution using PM method showed that according to the classification of N.A. Kachinsky Haplic Chernozem corresponded to a heavy loamy in all experimental variants. The content of the sum of fractions less than 0.01 $\mathrm{mm}$ in the control was $48.1 \%$, varying within the range of $6.8 \%$ (44.4-51.2\%) (Fig. 1). In this case, the taxonomic unit of particle size distribution remained unchanged. Variation of the fraction less than $0.001 \mathrm{~mm}$ was $15.6 \%$. The maximum fraction content of less than $0.001 \mathrm{~mm}$ was noted in the variant with the introduction of $2000 \mathrm{mg} / \mathrm{kg} \mathrm{Cu}(31.4 \%)$ into the 
soil. The minimum was noted in the variants with the addition of GAC at a dose of $2.5 \%$ and combined introduction of $\mathrm{Cu}$ at a dose of $300 \mathrm{mg} / \mathrm{kg}+\mathrm{GAC} 2.5 \%$ which accounted for $16.8 \%$ and $15.8 \%$, respectively.

The main changes in the quantitative content were revealed for small fractions of less than 0.001 mm, 0.001-0.005 mm, 0.005-0.01 mm.

The particles are sorted by shape and size in the process of formation of natural undisturbed soils. On the contrary, contaminated soils are often formed by a mixture of various materials The particle size distribution, under contamination with HMs, can reveal a change due to the chemical reactions between the mineral particles of the soil and the pollutant [5]. Changes in the distribution of particle size fractions are possible due to microaggregation. When HMs solutions enter the soil, the thickness of the double electric layer decreases. Hence, with the same amount of energy, the particles come together and become more condensed [13].

The differences in experimental variants can be due to two reasons: 1) the features of the determination method and 2) the influence of $\mathrm{Cu}$ and sorbents. The first reason is the use of weighted average density values when calculating the sedimentation rate using the Stokes formula. Particles with different values of density and diameter can potentially fall into one fractional sample. For example, particles of biochar and GAC with a low apparent density (not less than $0.37 \mathrm{~g} / \mathrm{cm}^{3}$ ) felt into a fraction of 0.001-0.005 $\mathrm{mm}$. So, in the variants with the addition of $2.5 \%$ GAC and $2.5 \%$ biochar, the content of this fraction increases by $7.2 \%$ and $5 \%$, respectively (Fig. 1). The second reason is associated with the behavior of the introduced $\mathrm{HM}$ in the soil. The absorption of the $\mathrm{Cu}^{2+}$ ion is largely carried out by the ion exchange mechanism [14]. The substitution of $\mathrm{Ca}^{2+}$ and $\mathrm{Fe}^{2+}$ ions for $\mathrm{Cu}^{2+}$ can increase the yield of finely dispersed fractions due to the formation of less stable organometallic complexes and partial destruction of the mineral organic compounds [15]. The maximum content of the silt fraction was established in the variant with the introduction of 2000 $\mathrm{mg} / \mathrm{kg} \mathrm{Cu}-31.4 \%$.

The introduction of carbon sorbents eliminated the effect of $\mathrm{Cu}$, bringing the data on the content of fractions closer to the control. However, due to different doses and also the adsorption characteristics of carbon sorbents, their effect was observed to be different (Fig. 1).

For LDM, the content of the sum of fractions in the Haplic Chernozem less than 0.01 $\mathrm{mm}$ was lower than in the PM - 30.6-42.5\%. The same result was observed for the amount of fraction less than $0.001 \mathrm{~mm}$ (Fig. 1). The difference in the results obtained by the two methods has been discussed in the literature [11, 16, 17].

Granulometric composition, as a multicomponent system, can be characterized using fundamental physical characteristics. In this regard, entropy $(H)$ [18] was calculated by the Shannon formula:

$\mathrm{H}=-\sum\left(\mathrm{x}_{\mathrm{i}} / \mathrm{G}\right) \log \mathrm{x}_{\mathrm{i}} / \mathrm{G}$, equation (1)

where $x_{i}$ is the content of the fraction, $G$ is the sum of all fractions.

The calculations showed a decrease in the average values of entropy relative to the control in both LDM and PM methods. It was found that the value of this indicator in PM was higher (1.96) than LDM (1.78).

Maximum entropy characterizes the uniform distribution of all fractions. A decrease in entropy indicates a high differentiation of particle size distribution when a predominance of one or more fractions is observed [18].

Significant correlation coefficients were established between the entropy and the content of fine sand $(0,05-0,25 \mathrm{~mm})(\mathrm{r}=0.79)$ in LDM and coarse silt $(0,01-0,05 \mathrm{~mm})(\mathrm{r}=$ $-0.54)$ and medium silt $(0,005-0,01 \mathrm{~mm})(\mathrm{r}=-0.59)$ in PM. 


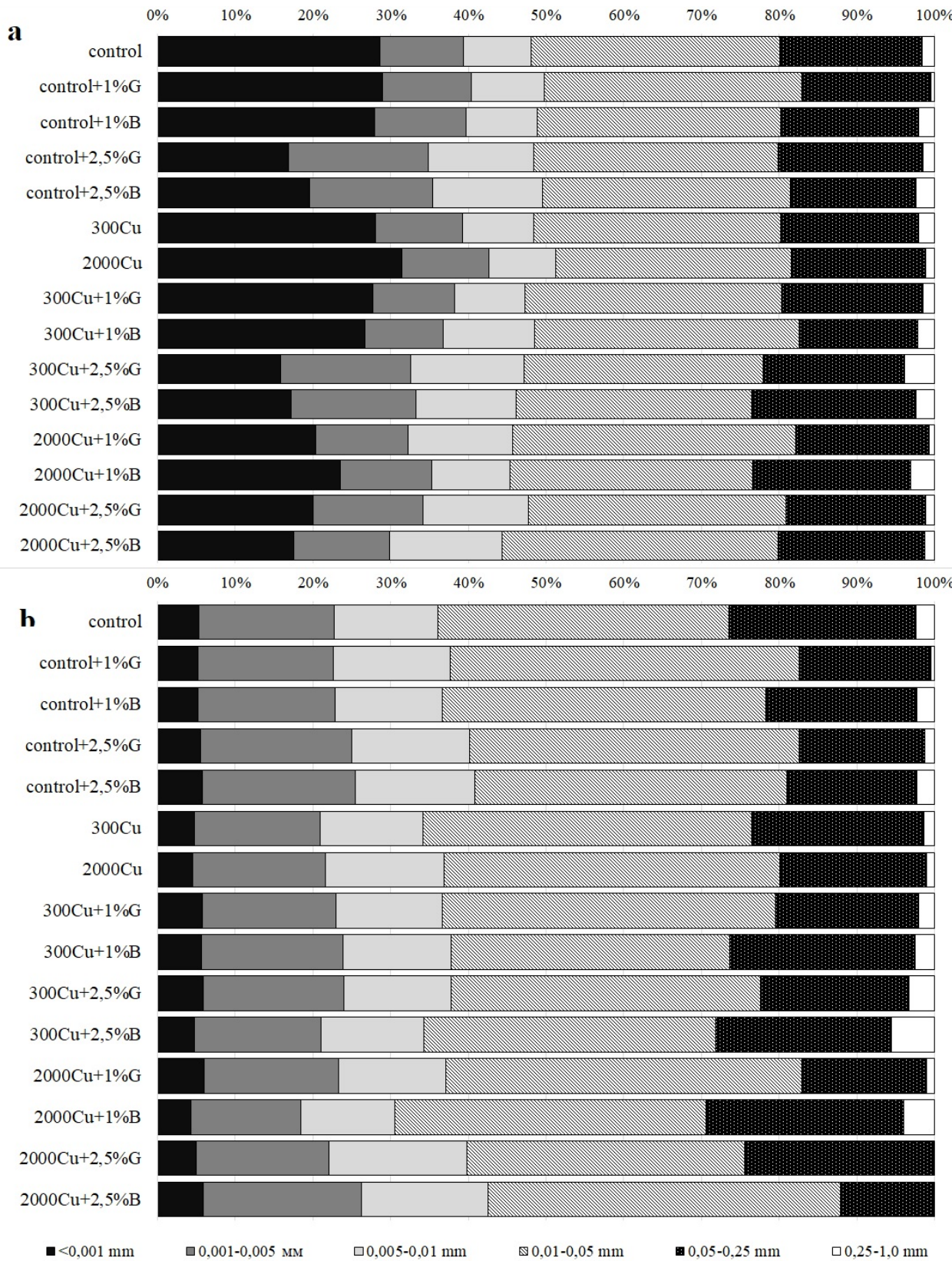

Fig. 1. Particle-size distribution of Haplic Chernozem contaminated with 300 and 2000 $\mathrm{mg} / \mathrm{kg} \mathrm{Cu}$ and adding different doses of biochar $(1 \% \mathrm{~B}$ and $2.5 \% \mathrm{~B})$ and GAC $(1 \% \mathrm{G}$ and $2.5 \% \mathrm{G})$ : a -data obtained by the pipette method (PM), b - data obtained by laser diffraction method (LDM)

The main difference in the experimental variants falls on fractions whose size exceeds $0.01 \mathrm{~mm}$ (i.e. $0.05-0.25 \mathrm{~mm}$, and $0.01-0.05 \mathrm{~mm}$ ). The principle of LDM is based on the scattering of electromagnetic waves. The angle of diffraction of the laser beam is inversely proportional to the size of the particles. The results obtained by this method reflect the true particle size distribution. The introduction of sorbents as new components of the solid 
phase, which have different sizes, played a major role in the redistribution of fractional composition. At the same time, the number of fractions less than $0.001 \mathrm{~mm}$ did not show difference according to the experimental variants.

\section{Conclusions}

By using two different methods of PM and LDM, dissimilar data have been obtained in terms of the particle size distribution. In the case of LDM, changes occurred in the group of fractions larger than $0.01 \mathrm{~mm}$. For PM, the change was observed for the group of a fraction of less than $0.01 \mathrm{~mm}$. This observation could be due to differences existed in the principles of the used methods. Using the LDM method gives a real picture of the particle size distribution when sorbents are added.

This study was carried out with the financial support of the Russian Science Foundation in the framework of research project № 19-74-00085.

\section{References}

1. X. Zhao, B. Gao, D. Xu, L. Gao, S. Yin, Environ. Sci. Pollut. Res., 24, 20844-20858, (2017)

2. N. Barsova, G. Motuzova, K. Kolchanova, A. Stepanov, M. Karpukhin, T. Minkina, S. Mandzhieva, Chemistry and Ecology, 35:1, 86-101, (2019)

3. X. Fei, G. Christakos, R. Xiao, Z. Ren, Y. Liu, X. Lv, Sci. Total Environ., 661, 168177, (2019)

4. T.M. Minkina, G.V. Motuzova, O.G. Nazarenko, Eur. Soil Sc., 39, 720-726, (2006)

5. T.M. Minkina, D.L. Pinskii, I.V. Zamulina, D.G. Nevidomskaya, C. Gülser, S.S. Mandzhieva, T.V. Bauer, I.V. Morozov, S.N. Sushkova, R. Kizilkaya, J. Soils Sediments, 18(6), 2418-2430, (2018)

6. F. Verheijen, S. Jeffery, A.C. Bastos, M. Van Der Velde, I. Diafas, C. Parsons, Biochar application to soils: a critical scientific review of effects on soil properties, processes and functions, (Joint Research Centre, Ispra, 2009)

7. G. Baiamonte, C. De Pasquale, V. Marsala, G. Cimò, G. Alonzo, G. Crescimanno, P. Conte, J Soils Sediments, 15, 816-824, (2015)

8. S.D. Joseph, M. Camps-Arbestain, Y. Lin, P. Munroe, C.H. Chia, J. Hook, L. van Zwieten, S. Kimber, A. Cowie, B.P. Singh, J. Lehmann, N. Foidl, R.J. Smernik, and J.E. Amonett, Aust. J. Soil Res., 48, 501-515 (2010)

9. D. Fischer, B. Glaser Synergisms Between Compost and Biochar for Sustainable Soil Amelioration, (INTECH Open Access Publisher, 2012)

10. L.D. Burrell, F. Zehetner, N. Rampazzo, B. Wimmer, G. Soja, Geoderma, 282, 96-102 (2016)

11. G.N. Fedotov, E.V. Shein, V.I. Putlyaev, T.A. Arkhangel'skaya, A.V. Eliseev, E.Yu. Milanovskii, Eur. Soil Sci., 40, 281-288, (2007)

12. Bittelli M., M.C. Andrenelli, G. Simonetti, S. Pellegrini, G. Artioli, I. Piccoli and F. Morari, Soil and Tillage Research, 185, 36-46, (2019)

13. J.C. Santamarina, K.A. Klein, M. Fam Soils and Waves: Particulate Materials Behavior, Characterization and Process Monitoring (J. Wiley \& Sons, New York, 2001)

14. A.A. Ponizovskii, T.A. Studenikina, E.V. Mironenko, Eur. Soil Sci.., 32(7), 766-775, (1999) 
15. Motuzova G.V., Makarychev I.P., Dergham H.M., Stepanov A.A., Barsova N.U. Soil organic matter and their interactions with metals: processes, factors, ecological significance (Nova Science Publishers, New York, 2012)

16. A.V. Yudina, D.S. Fomin, A.D. Kotelnikova, E.Y. Milanovskii, Eur. Soil Sci., 51(11), 1326-1347, (2018)

17. G. Eshel, G.J. Levy, U. Mingelgrin, M.J. Singer, Soil Sci. Soc. Am. J., 68, 736-743, (2004)

18. Yu. N. Vodianitskiy, Sov. Soil Sci., 11, 105-110, (1986) 